\title{
African Dust Particles over the Western Caribbean Part I: Impact on air quality over the Yucatan Peninsula
}

Carolina Ramírez-Romero ${ }^{1}$, Alejandro Jaramillo ${ }^{1}$, María F. Córdoba ${ }^{1,2}$, Graciela B. Raga ${ }^{1}$, Javier Miranda ${ }^{3}$, Harry Alvarez ${ }^{4}$, Daniel Rosas ${ }^{5}$, Talib Amador ${ }^{5}$, Jong Sung Kim ${ }^{6}$,

5 Jacqueline Yakobi-Hancock ${ }^{6}$, Darrel Baumgardner ${ }^{7}$, and Luis A. Ladino ${ }^{1, *}$

${ }^{1}$ Centro de Ciencias de la Atmósfera, Universidad Nacional Autónoma de Mexico, Mexico City, Mexico.

${ }^{2}$ Posgrado en Ciencias Químicas, Universidad Nacional Autónoma de Mexico, Mexico City, Mexico.

${ }^{3}$ Instituto de Física, Universidad Nacional Autónoma de Mexico, Mexico City, Mexico.

$10 \quad{ }^{4}$ Facultad de Ciencias, Universidad Nacional Autónoma de Mexico, Mexico City, Mexico.

${ }^{5}$ Universidad Autónoma de Yucatan, Merida, Yucatán, Mexico.

${ }^{6}$ Dalhousie University, Halifax, Nova Scotia, Canada.

${ }^{7}$ Droplet Measurement Technologies, Colorado, USA

*Correspondence to: L.A.L (luis.ladino@atmosfera.unam.mx)

Supplementary information

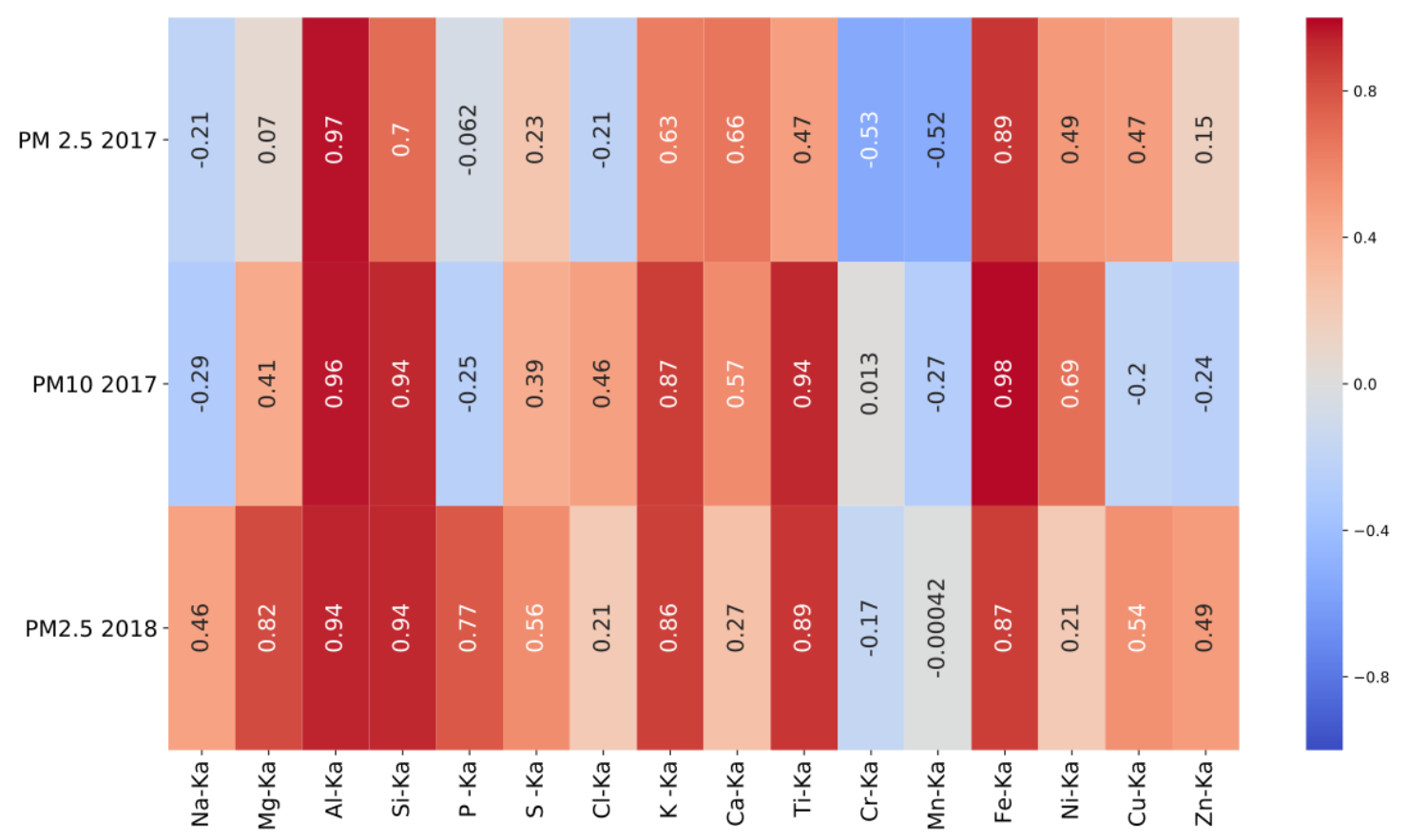

Figure S1. Correlation coefficients between $\mathrm{PM}_{2.5}$ and $\mathrm{PM}_{10}$ with each of the 16 elements analyzed by $\mathrm{X}$-ray fluorescence for both field campaigns. 


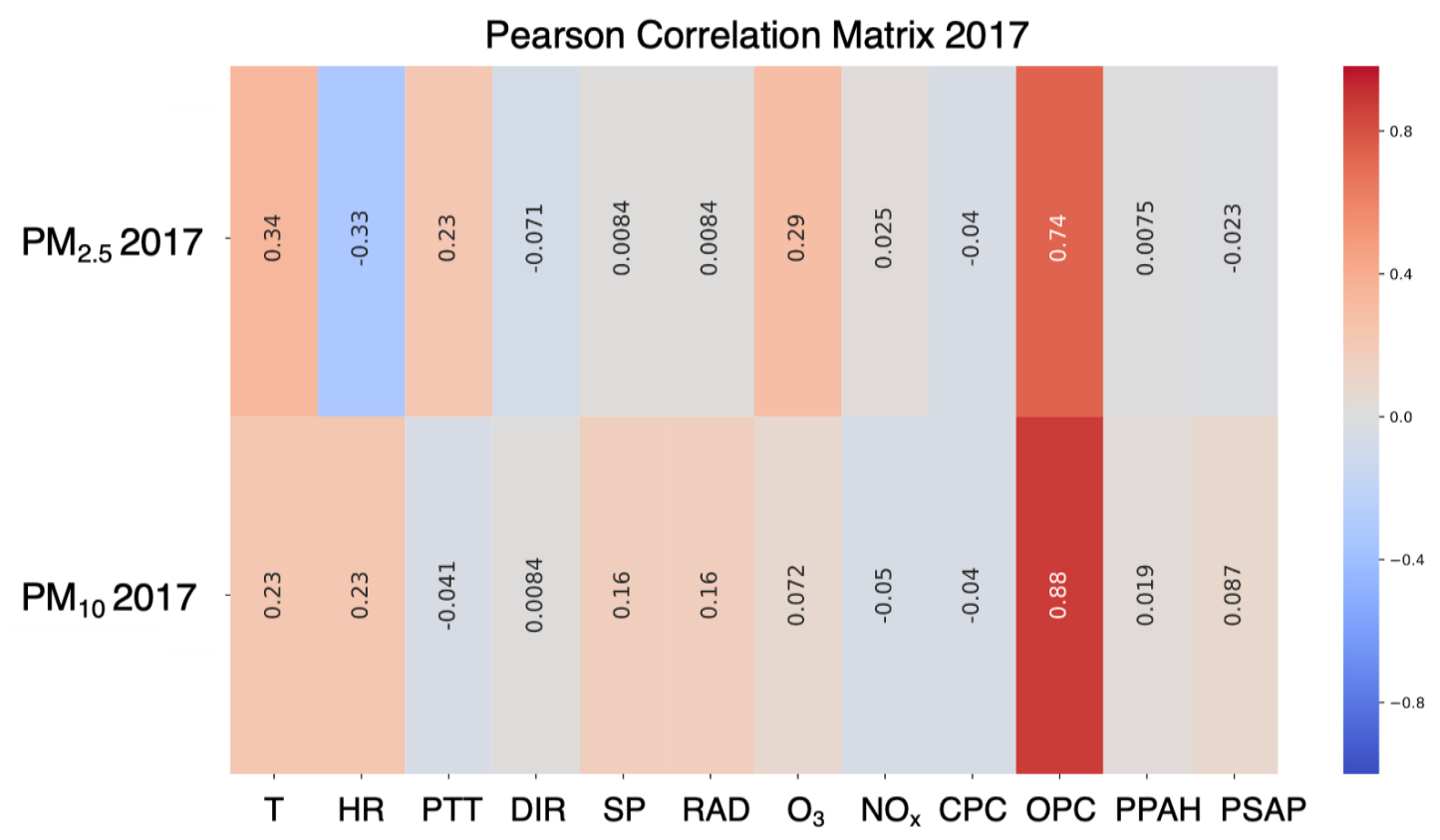

20 Figure S2. Correlation coefficients between $\mathrm{PM}_{2.5}$ and $\mathrm{PM}_{10}$ with other measured variables for 2017. T, RH, PTT, DIR, SP, RAD, $\mathrm{O}_{3}$, NOx, CPC, OPC PPAH, and PSAP refers to temperature, relative humidity, precipitation, wind direction, wind speed, solar radiation, ozone concentration, nitrogen oxides concentration, total particle concentration $(>30 \mathrm{~nm})$, "coarse" particle concentration $(>500 \mathrm{~nm})$, particle-bound polycyclic aromatic hydrocarbons concentration, and black carbon content, respectively.

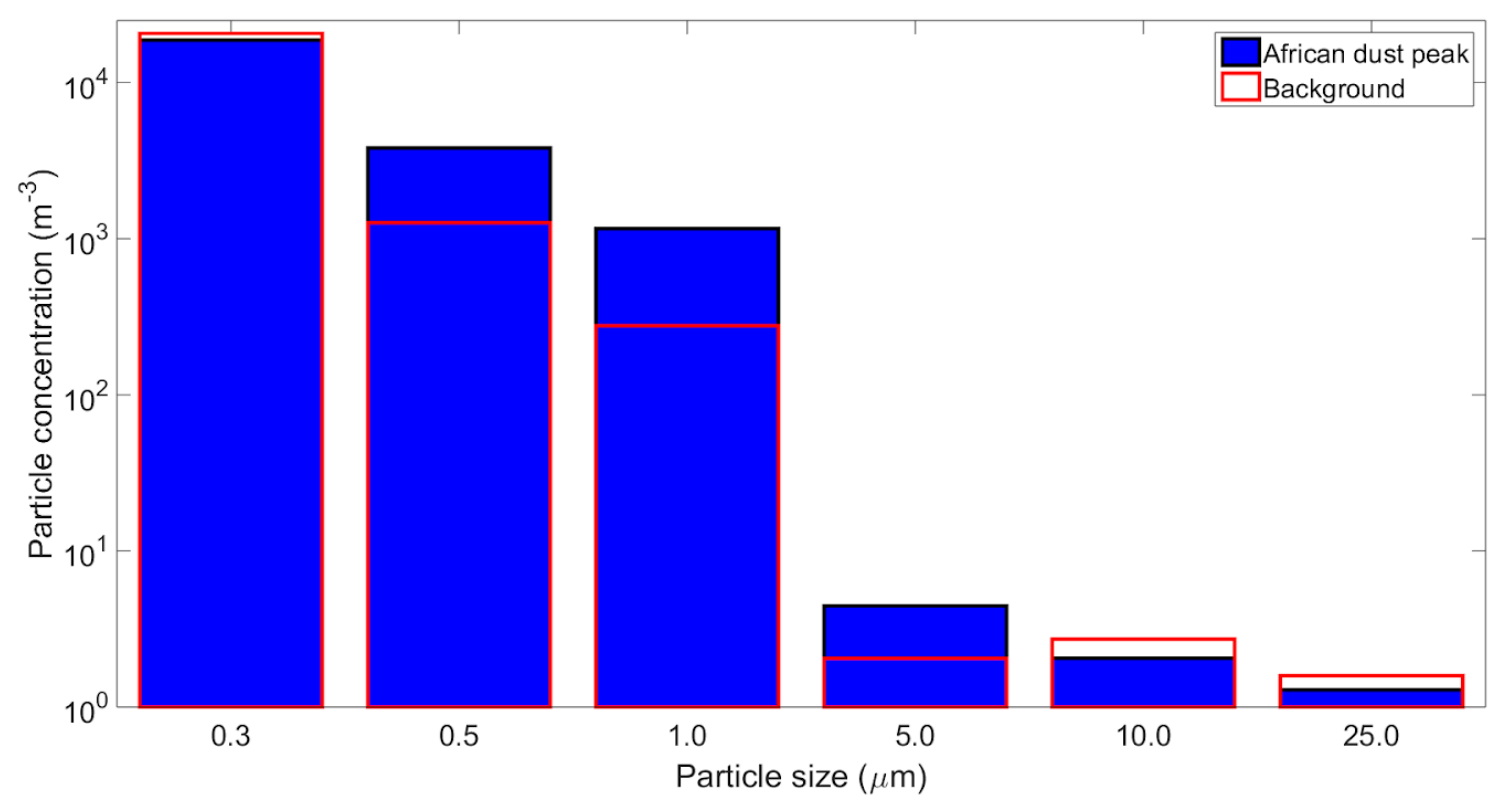

Figure S3. Particle size distribution before (red) and after (blue) the arrival of the African dust for the peak observed between July 22 and 24, 2017. 


\section{Pearson Correlation Matrix 2018}

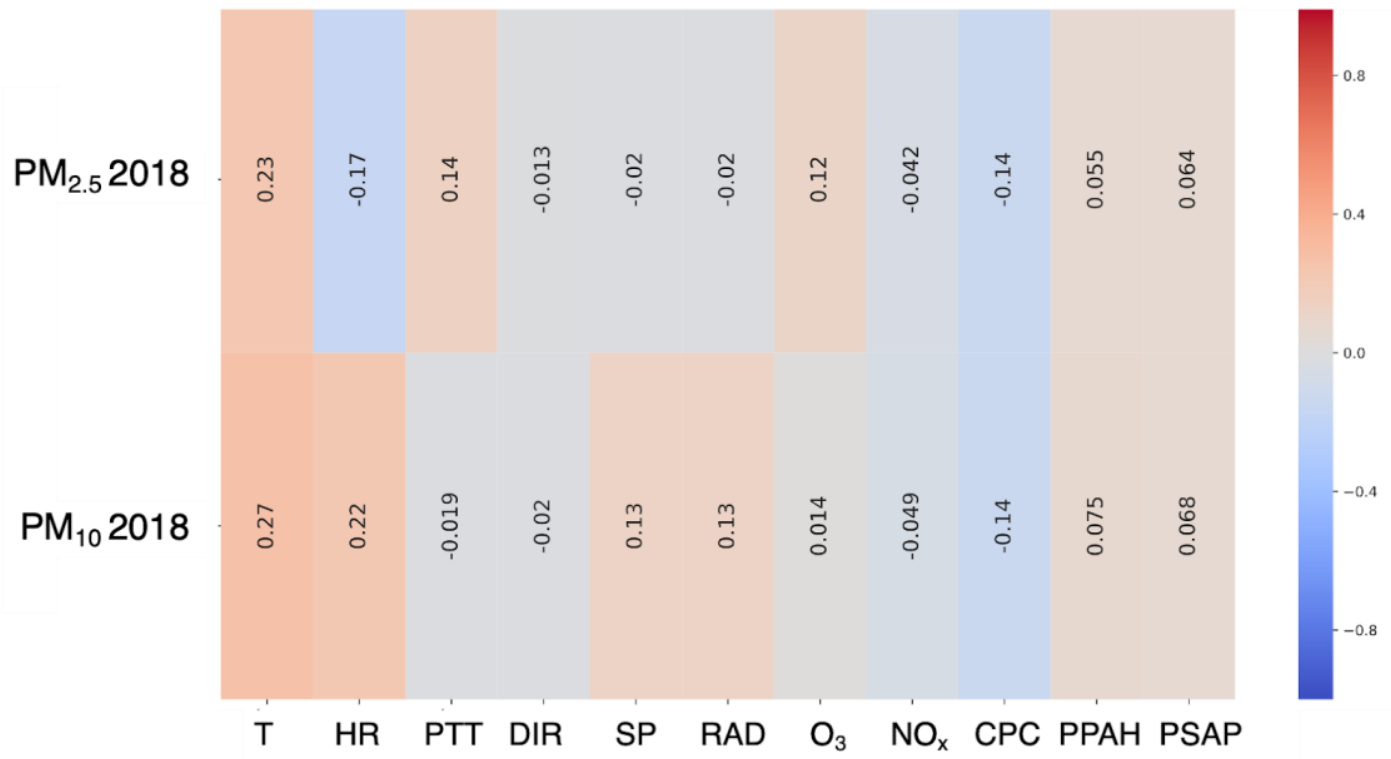

30 Figure S4. Correlation coefficients between $\mathrm{PM}_{2.5}$ and $\mathrm{PM}_{10}$ with other measured variables for 2018. T, RH, PTT, DIR, SP, RAD, $\mathrm{O}_{3}, \mathrm{NOx}, \mathrm{CPC}, \mathrm{PPAH}$, and PSAP refers to temperature, relative humidity, precipitation, wind direction, wind speed, solar radiation, ozone concentration, nitrogen oxides concentration, total particle concentration $(>30 \mathrm{~nm})$, particle-bound polycyclic aromatic hydrocarbons concentration, and black carbon content, respectively.

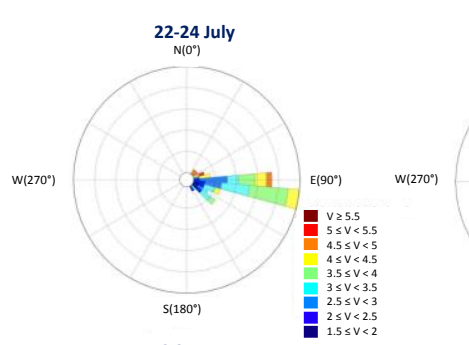

4 August

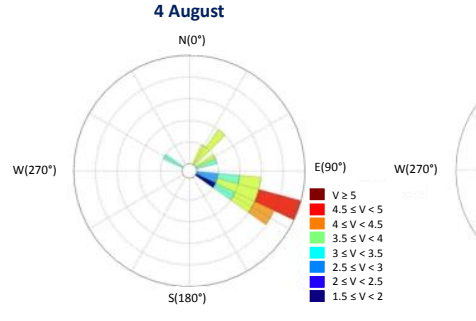

$\mathrm{s}\left(180^{\circ}\right)$

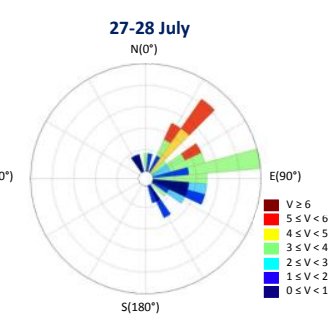

6-7 August

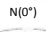

$\mathrm{N}\left(0^{\circ}\right)$

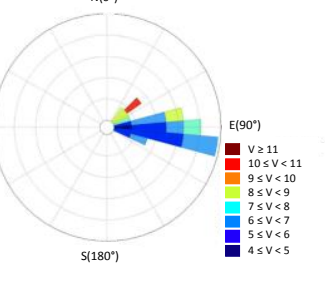

2017

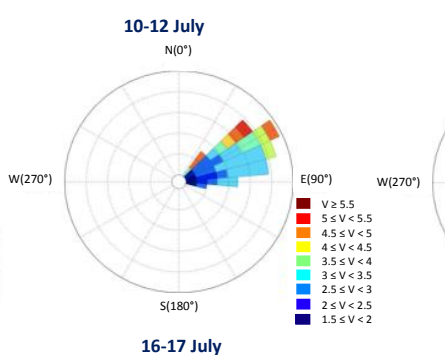

16-17 July

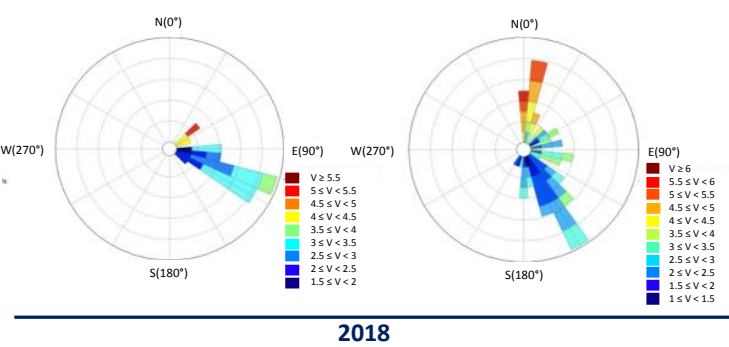

Figure S5. Wind roses of the average speed of the African dust peaks found in left) 2017 and, right) 2018 . 

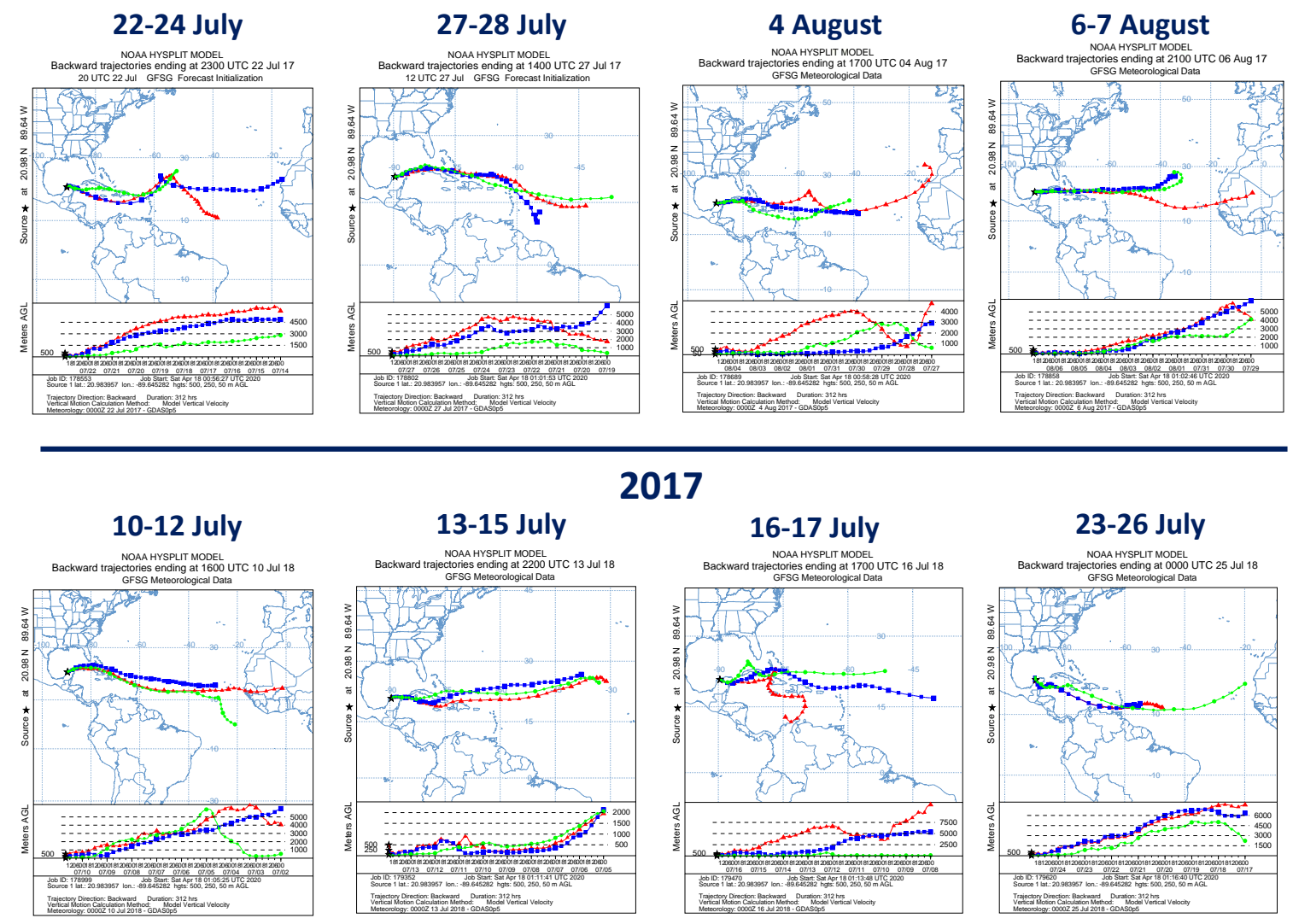

2017
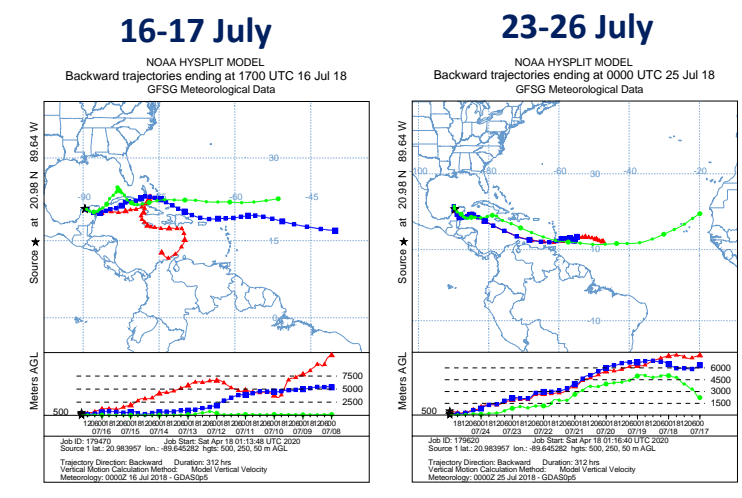

\section{8}

Figure S6. HYSPLIT back trajectories run for 13 days at $50 \mathrm{~m}$ (green), $250 \mathrm{~m}$ (blue), and $500 \mathrm{~m}$ (red) agl.

Top and bottom trajectories are related to the African dust peaks identified for 2017 and 2018, respectively.

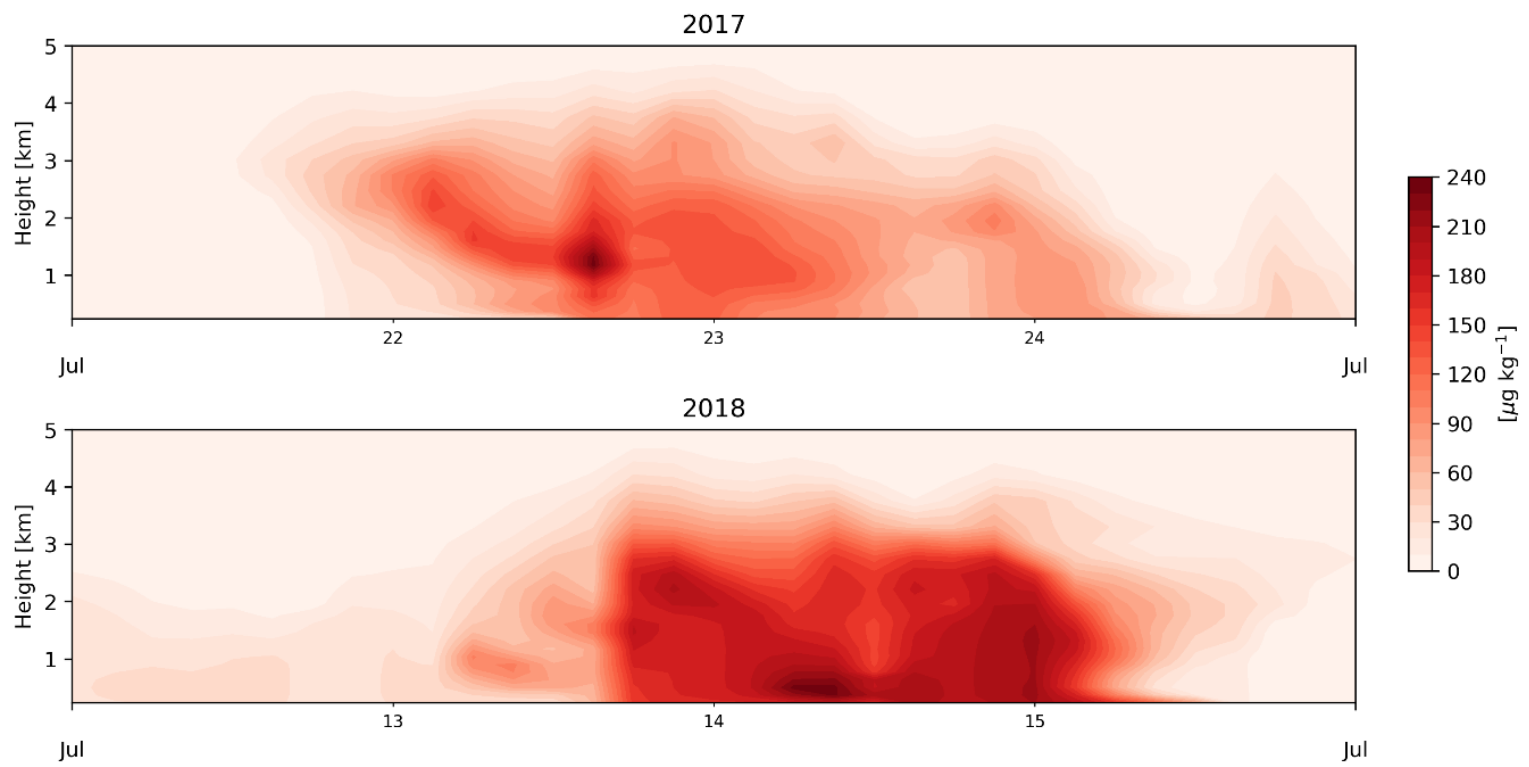

Figure S7. 3-hour time series of the vertical profile of the estimated dust content from MERRA-2 for July 21 to 25, 2017 period (above) and the July 12 to 16, 2018 period (below), showing dust arrival events in Mérida. 


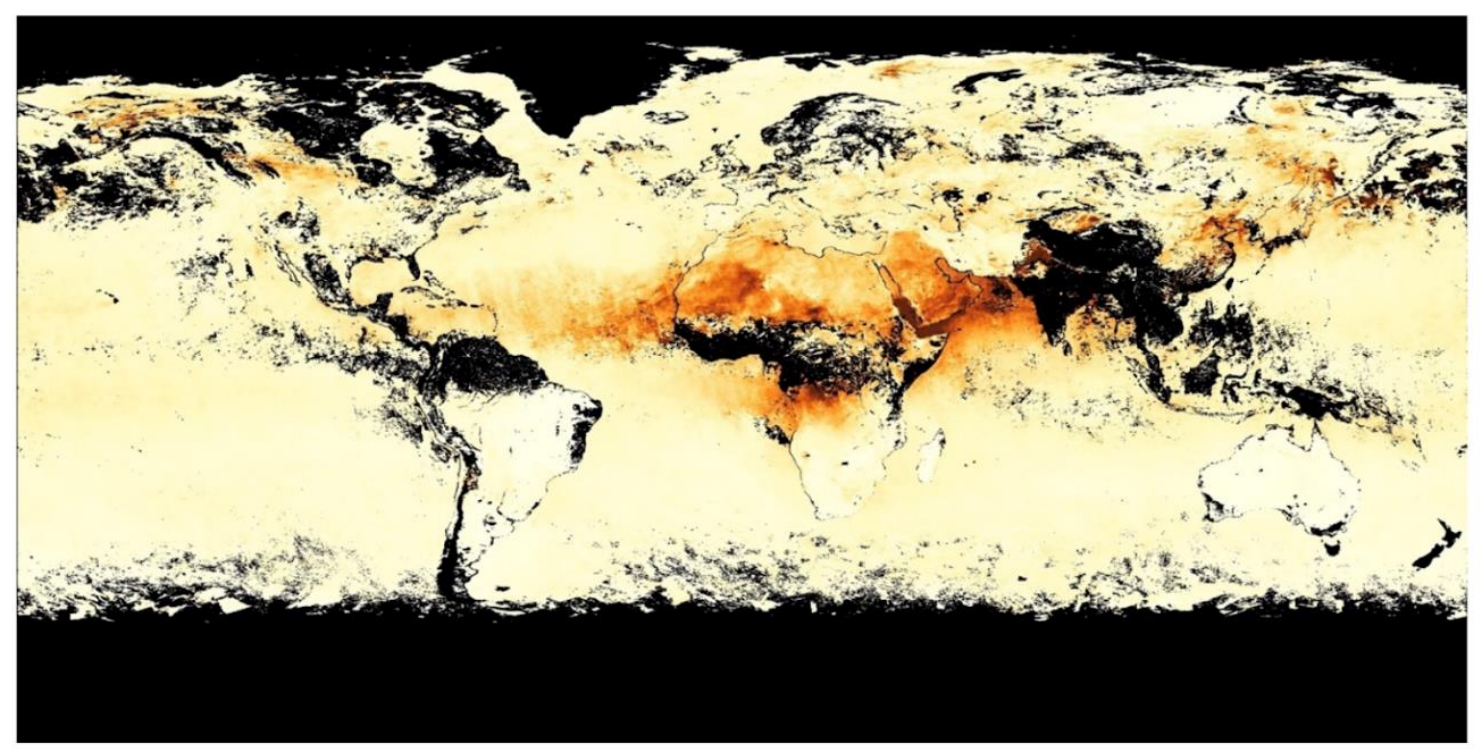

Figure S8. Aerosol optical depth (AOD) detected by the MODIS satellite for July 2017.

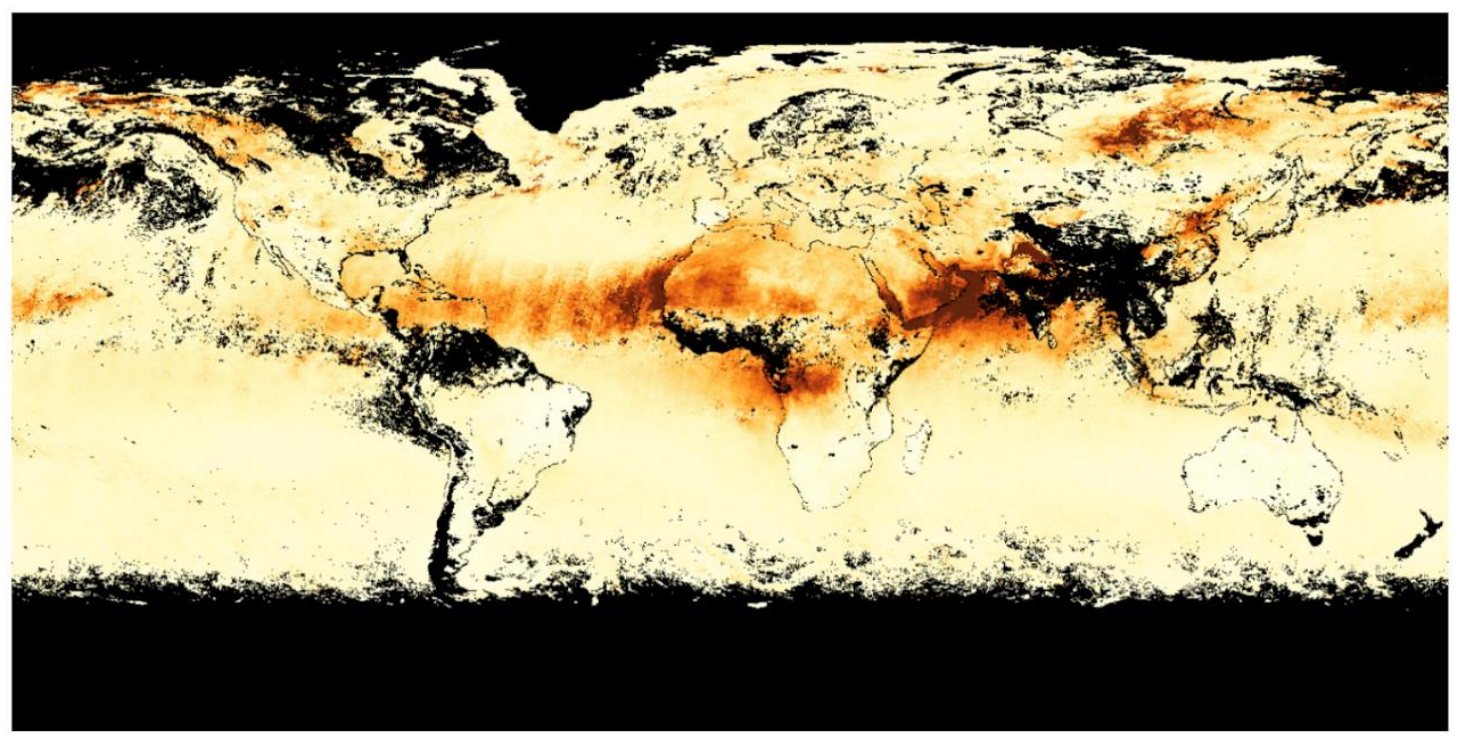

Figure S9. Aerosol optical depth (AOD) detected by the MODIS satellite for July 2018. 

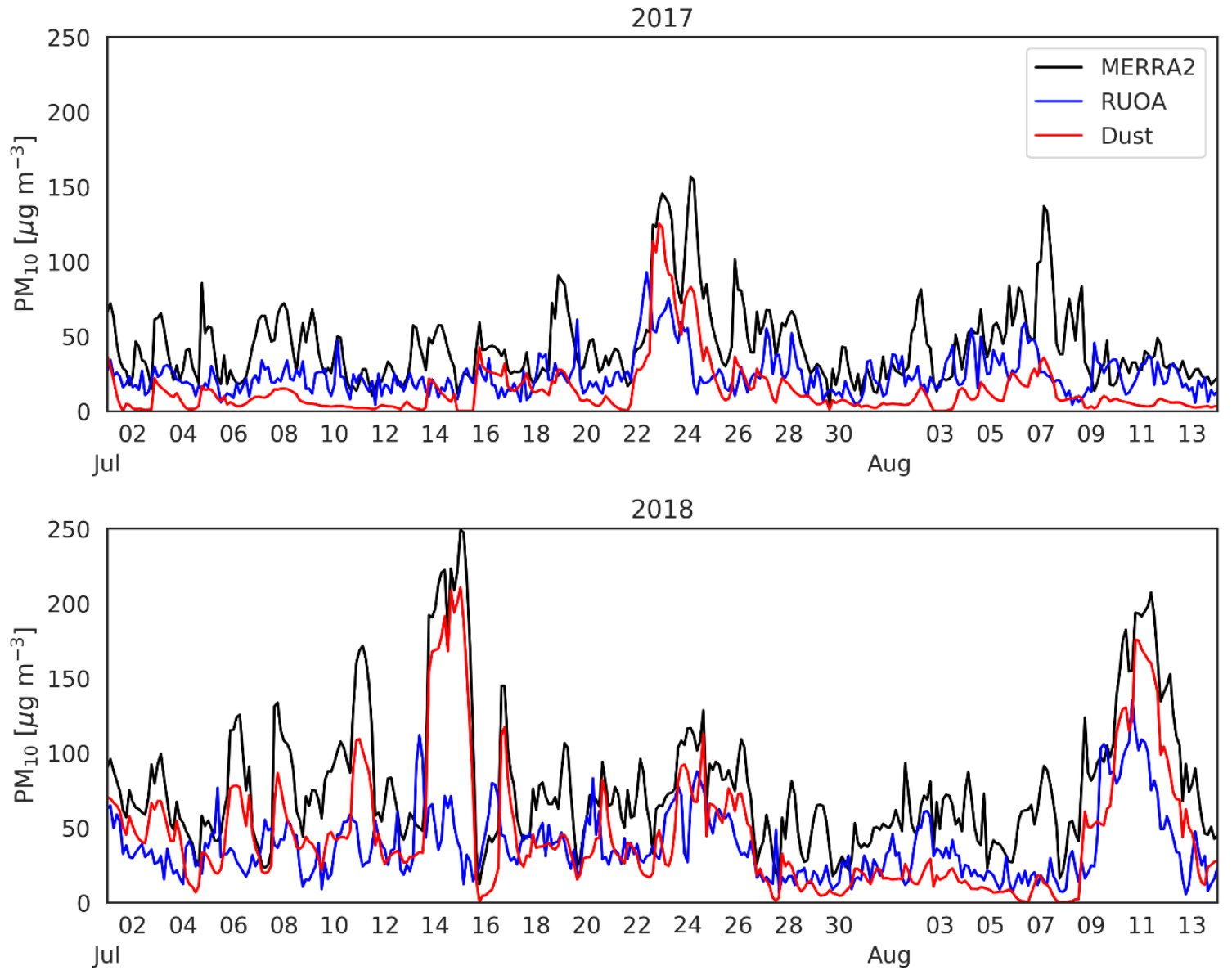

Figure S10. $3 \mathrm{~h} \mathrm{PM} 10$ estimated from MERRA-2 (black line), measured by the RUOA station (blue line), and estimated dust mixing ratio content of MERRA-2 (red line).
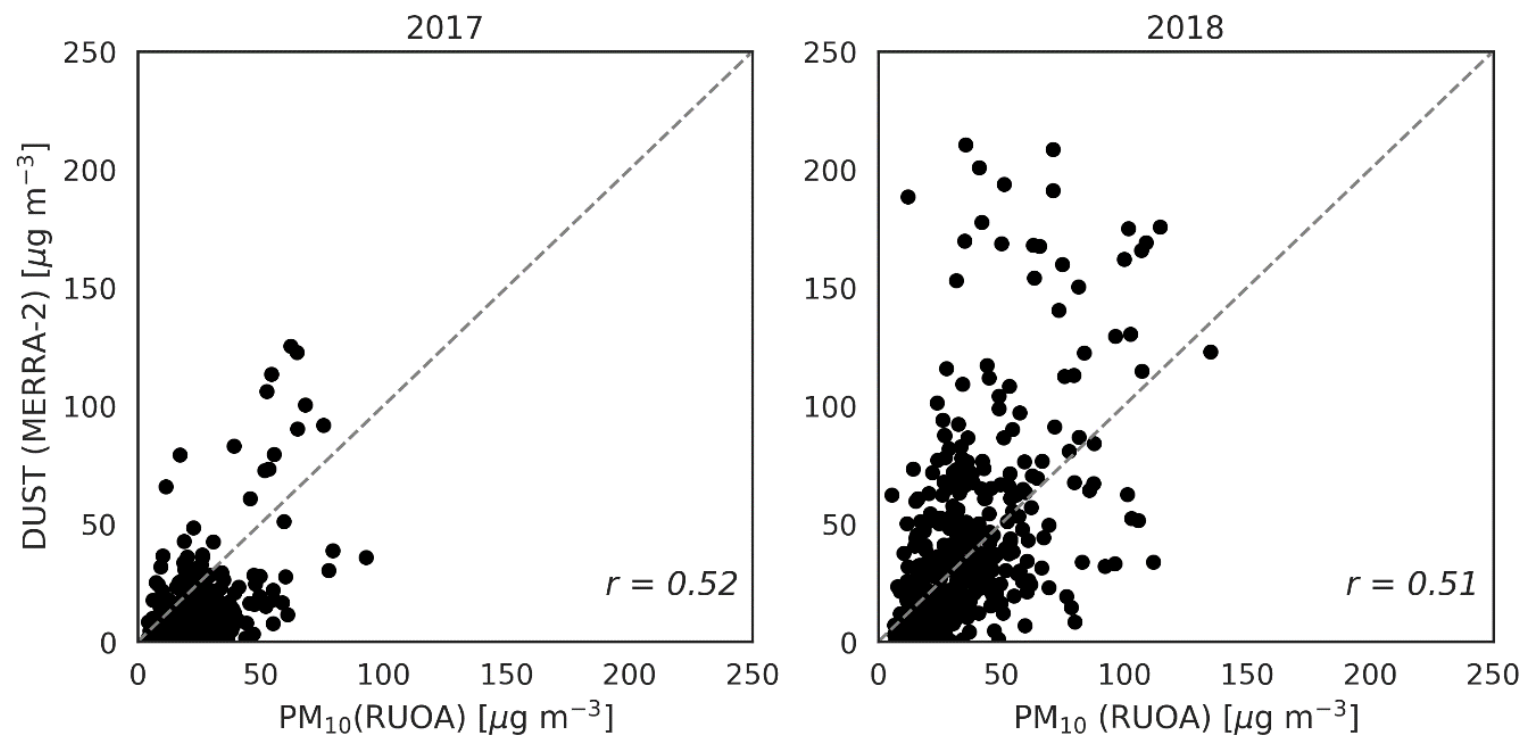

Figure S11. Dispersion plot of 3-H surface dust mixing ratio from MERRA-2 (y-axis) vs. the $\mathrm{PM}_{10}$ from the RUOA station for the periods shown in Figure 5 for a) 2017 and b) 2018. 